\title{
Access to 3D Alicyclic Amine-Containing Fragments through Transannular C-H Arylation
}

\author{
Melissa Lee ${ }^{\mathrm{a}}$ \\ Ashley Adams $^{\mathrm{b}}$ \\ Philip B. Cox \\ Melanie S. Sanford*a (D) \\ ${ }^{a}$ Department of Chemistry, University of Michigan, 930 North \\ University Avenue, Ann Arbor, Michigan 48109, USA \\ mssanfor@umich.edu \\ ${ }^{\mathrm{b}}$ Discovery Chemistry and Technology, AbbVie Inc., 1 North \\ Waukegan Road, North Chicago, Illinois, 60064, USA
}

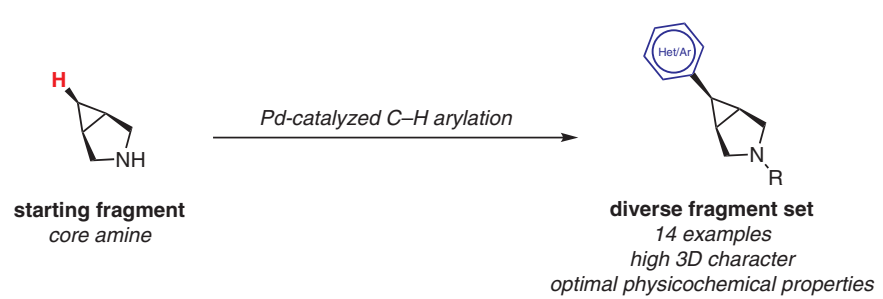

We sought to apply our Pd-catalyzed $\mathrm{C}\left(\mathrm{sp}^{3}\right)-\mathrm{H}$ arylation of alicyclic amines to the assembly of 3D fragments for FBDD. ${ }^{1}$ However, in order to rapidly access the desired fragments, we needed to address several challenges associated with the existing method. First, the current method requires relatively long reaction times $(18 \mathrm{~h})$, which impedes the rapid synthesis of analogues. Second, reaction conditions must be identified that are compatible with diverse coupling partners, particularly those containing heteroaromatics and halogenated functional groups. Finally, conditions must be established to rapidly remove the directing group tethered to nitrogen in order to release the desired amines.

Herein, we focus on addressing these challenges in the context of the transannular $\mathrm{C}\left(\mathrm{sp}^{3}\right)-\mathrm{H}$ functionalization of 3-azabicyclo[3.1.0]hexane to generate derivatives bearing aryl groups at the C-6 position. Notably, 3-azabicyclo[3.1.0] hexane serves as the core of a variety of bioactive molecules. ${ }^{6}$ The C-6-arylated derivatives are attractive fragments for FBDD, as they are rule-of-three compliant ( $\mathrm{MW}<300$; $\operatorname{Clog} \mathrm{P}<3$; hydrogen bond donors/acceptors $<3$; rotatable bonds $<3$, and TPSA $\left.<60 \mathrm{~A}^{2}\right)^{7}$ (Scheme 1 ), and they have a high degree of saturation and 3-D topology.

Traditionally, the assembly of 3-azabicyclo[3.1.0]hexane derivatives bearing functional groups at C-6 required long synthetic sequences. ${ }^{6 b, d}$ In contrast, the Pd-catalyzed transannular $\mathrm{C}-\mathrm{H}$ arylation method enables selective functionalization at C-6 in just three steps: (1) directing group installation, (2) transannular $\mathrm{C}\left(\mathrm{sp}^{3}\right)-\mathrm{H}$ arylation, and (3) directing group removal.

This work aims to streamline the assembly of 3-azabicyclo[3.1.0]hexane fragments by: (1) decreasing reaction times in order to increase reaction throughput and (2) increasing the efficiency and practicality of directing group 
removal. These advances have enabled the preparation of a variety of derivatives, whose physicochemical properties have been calculated.

The original conditions for the $\mathrm{C}-\mathrm{H}$ arylation of the 3azabicyclo[3.1.0] hexane substrate $\mathbf{S}-\mathbf{1}$ required $18 \mathrm{~h}$ at $130{ }^{\circ} \mathrm{C}$ and also involved reaction set-up in a $\mathrm{N}_{2}$-atmosphere glovebox. Thus, we first sought to develop conditions to accelerate these transformations and to eliminate the need for a glovebox. ${ }^{10,8}$ As shown in Scheme 2, we found that the Pd-catalyzed $\mathrm{C}-\mathrm{H}$ arylation of $\mathbf{S}-\mathbf{1}$ proceeds in less than $1 \mathrm{~h}$ at $180^{\circ} \mathrm{C}$ with microwave heating to afford $\mathbf{1}$ in $68 \%$ yield. Importantly, this reaction could be set up on the bench top and then flushed with $\mathrm{N}_{2}$ for 1 min prior to heating. The yield under these conditions compares favorably to that obtained in the original report (74\%). ${ }^{1 \mathrm{a}}$ Furthermore, an improved yield of $83 \%$ was obtained when the scale was doubled from 0.52 to $1.04 \mathrm{mmol}$ of $\mathbf{S - 1} .^{9}$

The scope of aryl and heteroaryl iodide coupling partners was next explored under these modified reaction conditions. A variety of aryl iodides proved compatible, providing 6-aryl-3-azabicyclo[3.1.0]hexanes 2-9 in moderate to good yields (Scheme 2). Aryl iodides containing halogen, ether, and unprotected phenol groups could be employed under the microwave conditions. A variety of substituted pyridyl and quinolinyl iodides also reacted to afford modest to good yields of 10-16 (Scheme 2).

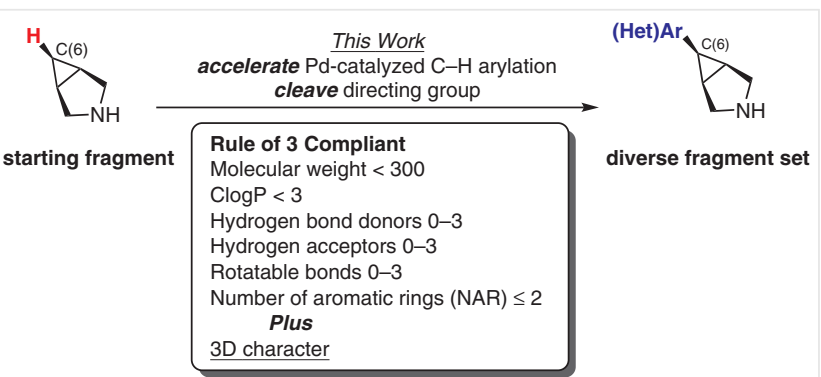

Scheme 1 Proposed synthesis of fragments through $\mathrm{C}-\mathrm{H}$ functionalization

Products 1-16 would be highly attractive scaffolds for FBDD following cleavage of the fluoroamide directing group. As such, we next focused on developing practical methods for directing group removal. The original procedure involved reductive cleavage with $\mathrm{SmI}_{2}$, subsequent in situ protection of the $2^{\circ}$ amine with pivaloyl chloride, and then isolation of the resultant amide. ${ }^{1 a}$ The first issue with these conditions is the requirement for superstoichiometric quantities of toxic HMPA as an activator for $\mathrm{SmI}_{2} \cdot{ }^{10} \mathrm{~A}$ second limitation is that this process yields amide products rather

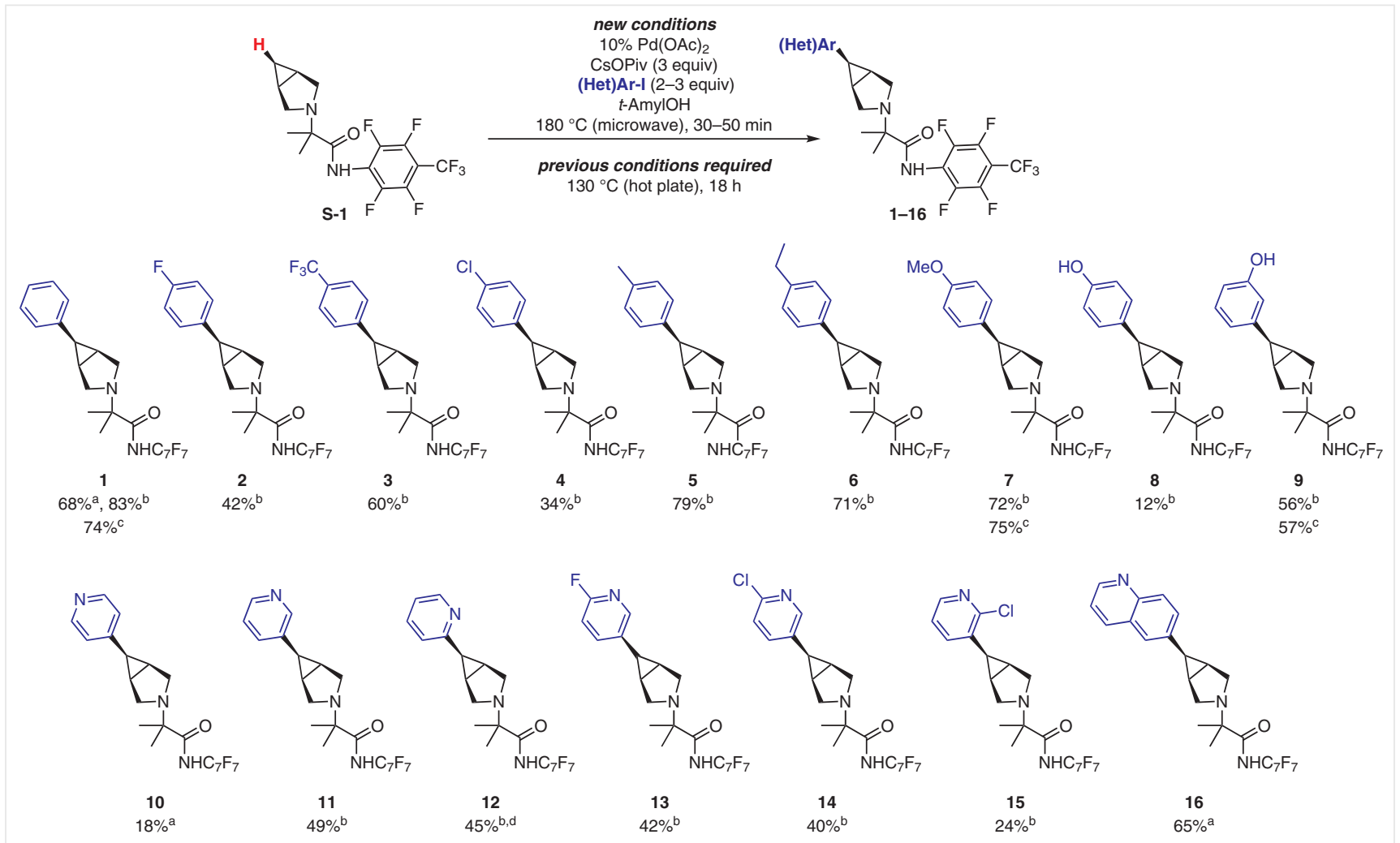

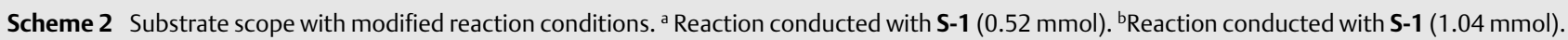

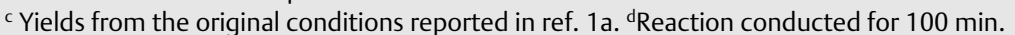


than the target amines. As such, we first targeted a modified procedure that replaces HMPA with a less toxic additive and also enables the direct isolation of amine products.

We explored alternative activators for $\mathrm{SmI}_{2}$ and identified tripyrrolidinophosphoric acid triamide (TPPA) as a viable replacement for HMPA. ${ }^{11}$ With this new activator, the directing group cleavage proceeds within $3 \mathrm{~h}$ at room temperature, compared to $24 \mathrm{~h}$ under the previous conditions. Further experimentation revealed that the $2^{\circ}$ amine product can be isolated by changing the workup procedure. Instead of adding pivaloyl chloride at the end of the $\mathrm{SmI}_{2}$ reaction, the crude mixture was subjected to an aqueous workup, and the product was then purified via reverse-phase HPLC. This procedure enabled isolation of a variety of $2^{\circ}$ amine products in yields ranging from $34-51 \%$ (Table 1). ${ }^{12,13}$ Notably, a slightly modified workup involving a Boc-protection step was required for the highly polar product $\mathbf{9 A}$.

Table 1 Removal of Directing Group via Reductive Cleavage with Sml

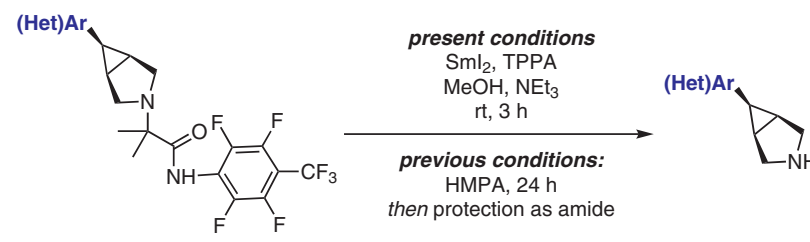

\begin{tabular}{lll}
\hline Entry & Product & Yield (\%) \\
\hline 1 & 4-Ph (1A) & 34 \\
2 & 4-F-Ph (2A) & 48 \\
3 & 4-CF - Ph (3A) & 44 \\
4 & 4-Me-Ph (5A) & 49 \\
5 & 4-Et-Ph (6A) & 39 \\
6 & 4-MeO-Ph (7A) & 51 \\
7 & 3-OH-Ph (9A) & $38^{\mathrm{a}}$ \\
8 & 3-Pyr (11A) & 0 \\
\hline
\end{tabular}

${ }^{\mathrm{a}}$ Deprotection followed by protection $\mathrm{Boc}_{2} \mathrm{O}$ and deprotection.

A limitation of the $\mathrm{SmI}_{2}$-mediated directing group cleavage process is that it is incompatible with substrates containing aryl halide functional groups. ${ }^{14}$ Additionally, pyridine derivatives such as $\mathbf{1 1}$ undergo heteroarene reduction in the presence of $\mathrm{SmI}_{2}{ }^{15}$ As such, we developed a complementary procedure to remove the directing group from these substrates. We hypothesized that acylation of the basic nitrogen could facilitate subsequent dealkylation of the fluoroamide directing group. ${ }^{16} \mathrm{~A}$ major challenge for this process is that the nitrogen center is very sterically hindered; as such, acylation requires relatively forcing reaction conditions. However, after some optimization, we found that the treatment of $\mathbf{1}$ with neat acetyl chloride under microwave heating at $150{ }^{\circ} \mathrm{C}$ for $3 \mathrm{~h}$ affords the amide product 1B in 35\% yield as determined by ${ }^{1} \mathrm{H}$ NMR spectroscopic analysis of the crude reaction mixture. 1B was isolated in $25 \%$ yield from this reaction. ${ }^{17}$

These conditions proved effective for cleaving the directing group from $\mathbf{1}$ and $\mathbf{4}$ as well as many of the pyridinecontaining derivatives in modest yields (12-25\%, Table 2). In the case of 10, complete consumption of starting material was observed, but the desired product 10B was not detected. This appears to be due to decomposition of $\mathbf{1 0}$ under these conditions, as the solution turned dark upon the addition of the acylating reagent. Notably, the aryl- $\mathrm{Cl}$ bonds of 4B, 14B, and 15B were compatible with these conditions (Table 2). However, product 13B was not isolable due to competing nucleophilic aromatic substitution to generate the 2-chloro product 14B.

Table 2 Removal of Directing Group through Acylative Dealkylation

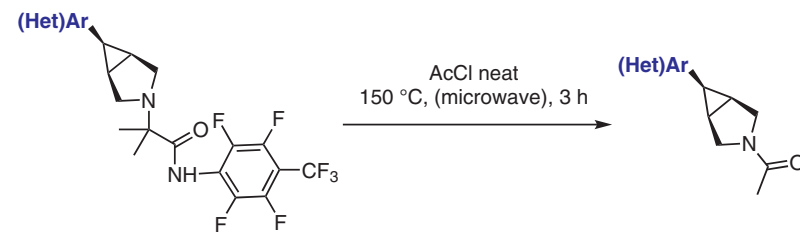

\begin{tabular}{lll}
\hline Entry & Product & Yield (\%) \\
\hline 1 & 4-Ph (1B) & 25 \\
2 & 4-ClPh (4B) & 25 \\
3 & 4-Pyr (10B) & 0 \\
4 & 3-Pyr (11B) & 19 \\
5 & 2-Pyr (12B) & 19 \\
6 & 2-F-5-Pyr (13B) & 0 \\
7 & 2-Cl-5-Pyr (14B) & 19 \\
8 & 2-Cl-3-Pyr (15B) & 12 \\
9 & 6-quinoline (16B) & 23 \\
\hline
\end{tabular}

We next assessed the physicochemical properties of the molecules in Tables 1 and 2 to assess their suitability for applications in FBDD. ${ }^{18}$ The calculations confirm that these 14 molecules fall within the ideal range for fragments, as defined by the restrictions set by the Rule of 3 and guidelines by Astex Pharmaceuticals (Table 3$)^{7}$ The fragments have a low mean molecular weight (204), while maintaining high levels of $\mathrm{Fsp}^{3}$ (fraction aromatic $=0.48$ ). In Figure 1 the molecular weights of the fragments are plotted against their ClogP values, demonstrating that most fall within the desirable range of $0-2$. 
Table 3 Physicochemical Properties of Fragment Set

\begin{tabular}{lll}
\hline Property & Ideal $^{7}$ & Fragment Set \\
\hline Clog $^{\mathrm{p}}$ & $0-2$ & 0.92 \\
molecular weight $^{140-230}$ & 204 \\
polar surface Area & $\leq 60$ & 22.8 \\
hydrogen bond acceptor & $\leq 3$ & 1.5 \\
hydrogen bond donor & $\leq 3$ & 0.57 \\
rotatable bond count & - & 1.2 \\
fraction aromatic & - & 0.48 \\
\hline
\end{tabular}

${ }^{a} \mathrm{cLog} \mathrm{P}=$ calculated octanol/ water partition coefficient. $\mathrm{b}\left(\mathrm{A}^{2}\right)$

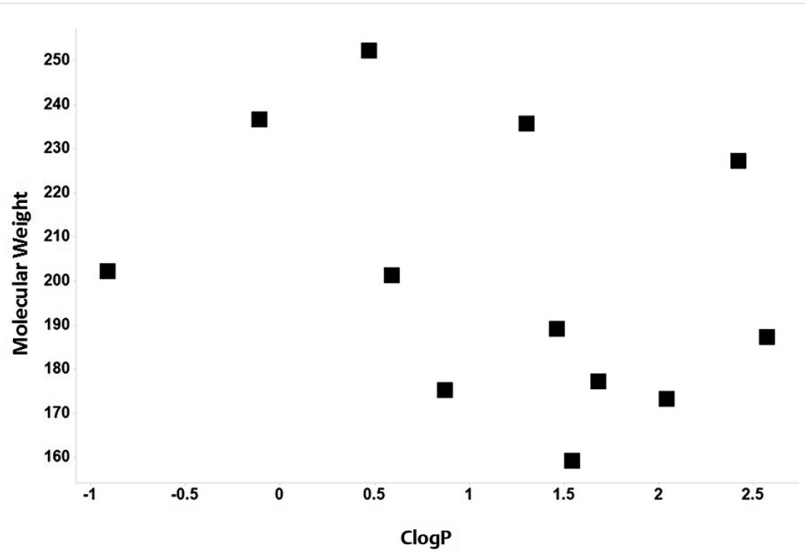

Figure 1 Plot of molecular weight versus ClogP

We also assessed two orthogonal topological descriptors for this set of fragments: the principal moments of inertia (PMI) ${ }^{19}$ and the plane of best fit score (PBF) ${ }^{20}$ These descriptors were calculated using AbbVie's internal design platform from Pipeline Pilot protocols employing published calculation methods. ${ }^{18-20}$ Based on the plot of the normalized principle moments of inertia (NPR1 and NPR2), the shapes of the molecules can be characterized as being rods, disks, or spheres (Figure 2). The combined PMI plot demonstrates that three of the compounds possess disc-like characteristics while the other 11 possess a rod- or sphere-like shape. The calculated mean NPR1+NPR2 (normalized principle moments of inertia) for this set of compounds is 1.24.

An arguably more granular topological descriptor for determining shape and, in particular, the 'three dimensionality' of molecules is the plane of best fit (PBF) score introduced by Firth et al. ${ }^{20}$ The PBF score calculates the distance from the theoretical PBF to the furthest atom of a molecule. The larger the distance (score), the more shape or three dimensionality a molecule possesses. The average PBF score

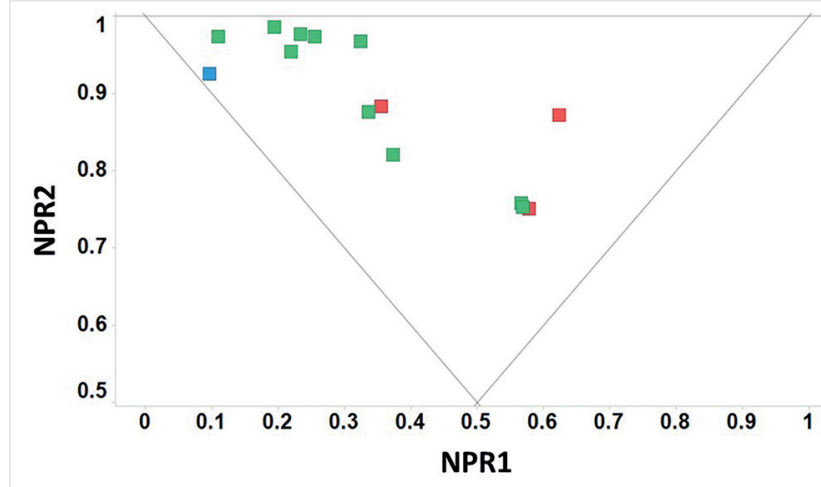

Figure 2 PMI plot for the C-6 arylated amines and amides synthesized. The average distance from the plane of best fit (PBF score) is denoted by the color of the markers (blue $\leq 0.50,0.50<$ green $\leq 0.75,0.75<$ red $\leq 1.00$ ).

for the synthesized fragments is 0.69 , indicating a high degree of three dimensionality. The PBF score of 15B is the highest at 0.87 , due to the substitution pattern on the pendant pyridyl ring. Molecules with combined PMI $(\mathrm{NPR} 1+\mathrm{NPR} 2)>1.07$ and a PBF $>0.6$ are considered to possess a high degree of 3D character. ${ }^{20}$ By this definition, all 14 fragments have a high degree of 3D character. Given that the majority of commercially available fragments are outside this area of 3D topological space (around 10\% of AbbVie's fragments are in this 3D compound space), these fragments represent a unique set of compounds with optimal physicochemical properties and atypical topology.

In conclusion, we demonstrate that the Pd-catalyzed C$\mathrm{H}$ arylation of the azabicyclo[3.1.0]hexane core provides rapid access to 3D fragments with attractive physicochemical properties for FBDD. Several key modifications were made to the catalysis conditions, including microwave heating to reduce reaction times and nitrogen purging to eliminate the need for a glove box. These changes increase the practicality of this method for library synthesis. In addition, new procedures were developed that increase the safety and practicality of removing the directing group while maintaining the integrity of the newly installed aryl/heteroaryl substituents. Computational analysis of the 14 amines/amides synthesized demonstrate that these compounds possess optimal physicochemical properties, including a high degree of saturation and 3D character. As such, they should serve as valuable additions to FBDD libraries and as potential scaffolds for early stage drug discovery efforts.

\section{Funding Information}

This work was supported by Abbvie as well as by the NIH NIGMS (GM073836). ML thanks the National Science Foundation and 
Rackham Graduate School for graduate fellowships. The authors declare the following competing financial interest(s): Ashley Adams and Phil Cox are employees of AbbVie. The design, study conduct, and financial support for this research were provided by AbbVie. AbbVie participated in the interpretation of data, review, and approval of the publication.

\section{Acknowledgment}

We thank Dr. Pablo Cabrera for helpful discussions on the $\mathrm{C}-\mathrm{H}$ arylation and protecting group removal procedures. We also thank the Abbvie high throughput purification team (Harry Spiwek, Tomas Galicia, and Anita McGreal) and Lei Shi for their assistance with purification as well as Noel Wilson for his assistance with the microwave instrument.

\section{Supporting Information}

Supporting information for this article is available online at https://doi.org/10.1055/s-0037-1610861.

\section{References and Notes}

(1) (a) Topczewski, J. J.; Cabrera, P. J.; Saper, N. I.; Sanford, M. S. Nature 2016, 531, 220. (b) Cabrera, P. J.; Lee, M.; Sanford, M. S. J. Am. Chem. Soc. 2018, 140, 5599.

(2) Daugulis, O.; Roane, J.; Tran, L. D. Acc. Chem. Res. 2015, 48, 1053.

(3) For papers and reviews on FBDD, see: (a) Hann, M. M.; Leach, A. R.; Harper, G. J. Chem. Inf. Comput. Sci. 2001, 41, 856. (b) Leach, A. R.; Hann, M. M. Curr. Opin. Chem. Biol. 2011, 15, 489. (c) Scott, D. E.; Coyne, A. G.; Hudson, S. A.; Abell, C. Biochemistry 2012, 51, 4990. (d) Erlanson, D. A.; Fesik, S. W.; Hubbard, R. E.; Jahnke, W.; Jhoti, H. Nat. Rev. Drug Discovery 2016, 15, 605. (e) Johnson, C. N.; Erlanson, D. A.; Jahnke, W.; Mortenson, P. N.; Rees, D. C. J. Med. Chem. 2018, 61, 1774 .

(4) (a) Lawrence, S. A. Amines: Synthesis, Properties and Applications; Cambridge University Press: Cambridge, 2004. (b) Dorwald, F. Z. Lead Optimization for Medicinal Chemists: Pharmacokinetic Properties of Functional Groups and Organic Compounds; 1st ed. Wiley-VCH: Weinheim, 2012. (c) Vitaku, E.; Smith, D. T.; Njardarson, J. T. J. Med. Chem. 2014, 57, 10257.

(5) (a) Murray, C. W.; Rees, D. C. Angew. Chem. Int. Ed. 2016, 55, 488. (b) Foley, D. J.; Nelson, A.; Marsden, S. P. Angew. Chem. Int. Ed. 2016, 55, 13650. (c) Morely, A. D.; Pugliese, A.; Birchall, K.; Bower, J.; Brennan, P.; Brown, N.; Chapman, T.; Drysdale, M.; Gilbert, I. H.; Hoelder, S.; Jordan, A.; Ley, S. V.; Merritt, A.; Miller, D.; Swarbrick, M. E.; Wyatt, P. G. Drug Discovery Today 2013, 18, 1221.

(6) (a) Epstein, J. W.; Brabander, H. J.; Fanshawe, W. J.; Hofmann, C. M.; McKenzie, T. C.; Safir, S. R.; Osterberg, A. C.; Cosulich, D. B.; Lovell, F. M. J. Med. Chem. 1981, 24, 481. (b) Lunn, G.; Roberts, E. L.; Content, S.; Critcher, S. D.; Fenwick, A. E.; Gethin, D. M.; Goodwin, G.; Greenway, D.; Greenwood, S.; Hall, K.; Thomas, M.; Thompson, S.; Williams, D.; Wood, G.; Wylie, A. Bioorg. Med. Chem. Lett. 2012, 22, 2200. (c) Bakonyi, B.; Furegati, M.; Kramer, C.; Vecchia, L. L.; Ossola, F. J. Org. Chem. 2013, 78, 9328. (d) Runyon, S. P.; Kormos, C. M.; Gichinga, M. G.; Mascarella, S. W.; Navarro, H. A.; Deschamps, J. R.; Imler, G. H.; Carroll, F. I. J. Org. Chem. 2016, 81, 10383. (e) Jones, S.; Ahmet, J.; Ayton, K.; Ball, M.; Cockerill, M.; Fairweather, E.; Hamilton, N.; Harper, P.;
Hitchin, J.; Jordon, A.; Levy, C.; Lopez, R.; McKenzie, E.; Packer, M.; Plant, D.; Simpson, I.; Simpson, P.; Sinclair, I.; Somervaille, T. C. P.; Small, H.; Spencer, G. J.; Thomson, G.; Tonge, M.; Waddell, I.; Walsh, J.; Waszkowycz, B.; Wigglesworth, M.; Wiseman, D. H.; Ogilvie, D. J. Med. Chem. 2016, 59, 11120. (f) Harris, M. R.; Li, Q.; Lian, Y.; Xiao, J.; Londregan, A. T. Org. Lett. 2017, 19, 2450.

(7) (a) Congreve, M.; Carr, R.; Murray, C.; Jhoti, H. Drugs Discovery Today 2003, 8, 876. (b) Palmer, N.; Peakman, T. M.; Norton, D.; Rees, D. C. Org. Biomol. Chem. 2016, 14, 1599.

(8) Lew, A.; Krutzik, P. O.; Hart, M. E.; Chamberlin, R. A. J. Comb. Chem. 2002, 4, 95.

(9) General Procedure for Arylation of S-1

To a large microwave tube (Biotage ${ }^{\circledR}, 10-20 \mathrm{~mL}$ ) equipped with a stir bar was added $\mathrm{Pd}(\mathrm{OAc})_{2}(23.4 \mathrm{mg}, 0.10 \mathrm{mmol}, 10 \mathrm{~mol} \%)$, S1 (400 mg, $1.04 \mathrm{mmol}, 1$ equiv), cesium pivalate ( $731 \mathrm{mg}, 3.12$ mmol, 3 equiv), aryl iodide (2-3 equiv), and anhydrous tertamyl alcohol $(9.6 \mathrm{~mL})$. The cap was crimped, and the vessel was flushed with nitrogen. The microwave tube was heated with the following parameters: 1 min pre-stirring, followed by a ramp (normal) to $180{ }^{\circ} \mathrm{C}$, and held at temperature for 30-50 min. Hydrazine ( $500 \mu \mathrm{L}$ of $35 \% \mathrm{aq}$ ) was added to the reaction and allowed to stir at $60{ }^{\circ} \mathrm{C}$ for $1 \mathrm{~h}$ or at room temperature overnight. The tert-amyl alcohol was removed in vacuo, and the resulting residue was dissolved in EtOAc, filtered through a plug of Celite, and concentrated under vacuum. The crude reaction was purified via flash column chromatography, eluting with EtOAc/heptanes. Isolated yield of compound 2: $42 \%$ (210.2 mg). LC-MS: $\mathrm{APCI}^{+}: m / z[\mathrm{M}+\mathrm{H}]^{+}$calcd for $\mathrm{C}_{22} \mathrm{H}_{19} \mathrm{~F}_{8} \mathrm{~N}_{2} \mathrm{O}: 479.129$; found: 479.119. ${ }^{1} \mathrm{H}$ NMR $\left(\mathrm{CDCl}_{3}, 500 \mathrm{MHz}\right): \delta=7.27(\mathrm{~m}, 2 \mathrm{H})$, $6.78(\mathrm{t}, J=8.5 \mathrm{~Hz}, 2 \mathrm{H}), 6.48(\mathrm{br} \mathrm{s}, 1 \mathrm{H}), 2.94(\mathrm{~d}, J=9.0 \mathrm{~Hz}, 2 \mathrm{H})$, 2.89 (ddd, $J=9.0,2.0 \mathrm{~Hz}, 1.0 \mathrm{~Hz}, 2 \mathrm{H}), 2.04(\mathrm{t}, J=8.0 \mathrm{~Hz}, 1 \mathrm{H}$ ), $1.87(\mathrm{~m}, 2 \mathrm{H}), 1.14(\mathrm{~s}, 6 \mathrm{H}) .{ }^{13} \mathrm{C} \mathrm{NMR}\left(\mathrm{CDCl}_{3}, 126 \mathrm{MHz}\right): \delta=175.7$, $\left.161.1\left(\mathrm{~d}, J_{\mathrm{C}-\mathrm{F}}=246 \mathrm{~Hz}\right), 133.7,129.6\left(\mathrm{~d}, J_{\mathrm{C}-\mathrm{F}}=7.6 \mathrm{~Hz}\right) \mathrm{Hz}\right), 61.1$, $45.1,27.1,22.2,20.9 .20 .1$. The carbon resonances of the directing group (perfluoroarene, $\mathrm{C}_{7} \mathrm{~F}_{7}$ ) appear as complex multiplets and are not listed. ${ }^{19} \mathrm{~F} \mathrm{NMR}\left(\mathrm{CDCl}_{3}, 376 \mathrm{MHz}\right): \delta=-56.1(\mathrm{t}, J=$ $21.8 \mathrm{~Hz}, 3 \mathrm{~F}),-116.4$ (m, $1 \mathrm{~F}),-141.4$ (m, 2 F), -143.1 (m, 2 F).

(10) Kimbrough, R.; Gaines, T. R. Nature 1966, 211, 146.

(11) McDonald, C. E.; Ramsey, J. D.; Sampsell, D. G.; Butler, J. A.; Cecchini, M. R. Org. Lett. 2010, 12, 5178.

(12) General Procedure for Directing Group Removal with $\mathbf{S m I}_{\mathbf{2}}$ To a round-bottom flask under a flow of nitrogen was added the starting material (1 equiv), $0.1 \mathrm{M} \mathrm{SmI}_{2}$ (12 equiv), anhydrous triethylamine ( 80 equiv), anhydrous methanol (40 equiv), and $\operatorname{tris}(\mathrm{N}, \mathrm{N}$-tetramethylene)phosphoric acid triamide (5.5 equiv). The reaction was allowed to stir at room temperature for $3 \mathrm{~h}$. The reaction vessel was then exposed to air, and a white precipitate was observed within $30 \mathrm{~min}$. The reaction was quenched with $1 \mathrm{~N} \mathrm{HCl}$. To this mixture was added ethyl acetate, and the product was extracted into the aqueous acidic layer. The organic layer was set aside, and the aqueous layer was basified with solid $\mathrm{NaOH}$ until $\mathrm{pH} 11-12$. The aqueous layer was extracted with ethyl acetate $(3 \times 100 \mathrm{~mL})$ and dried over sodium sulfate. After the volatiles were removed, a viscous yellow oil remained and was purified by reverse-phase HPLC (Waters XBridge ${ }^{\mathrm{TM}} \mathrm{C}$ 18 column, $5 \mu \mathrm{m}, 30 \times 100 \mathrm{~mm}$, flow rate $40 \mathrm{~mL} / \mathrm{min}, 5-100 \%$ gradient of acetonitrile in buffer $(0.025 \mathrm{M}$ aq ammonium bicarbonate, adjusted to $\mathrm{pH} 10$ with ammonium hydroxide or $0.1 \%$ TFA)). Isolated yield of compound 2A: 49\% (57.9 mg). LC-MS: $\mathrm{APCI}^{+}: m / z\left[\mathrm{M}+\mathrm{H}^{+}\right.$calcd for $\mathrm{C}_{11} \mathrm{H}_{13} \mathrm{FN}$ : 178.103; found: 178.069. ${ }^{1} \mathrm{H} \mathrm{NMR}\left(\mathrm{CDCl}_{3}, 400 \mathrm{MHz}\right): \delta=10.85(\mathrm{br} \mathrm{s}, 1 \mathrm{H}), 7.19(\mathrm{t}$, $J=8.4 \mathrm{~Hz}, 2 \mathrm{H}), 7.08(\mathrm{t}, J=8.4 \mathrm{~Hz}, 2 \mathrm{H}), 5.94(\mathrm{br} \mathrm{s}, 1 \mathrm{H}), 3.58(\mathrm{~d}$, $J=11.2 \mathrm{~Hz}, 2 \mathrm{H}), 3.30$ (d, $J=11.2 \mathrm{~Hz}, 2 \mathrm{H}), 2.39(\mathrm{t}, J=8.0 \mathrm{~Hz}, 1 \mathrm{H})$, 
$2.22(\mathrm{~m}, 2 \mathrm{H}) \cdot{ }^{13} \mathrm{C} \mathrm{NMR}\left(\mathrm{CDCl}_{3}, 101 \mathrm{MHz}\right): \delta=162.6\left(\mathrm{~d}, J_{\mathrm{C}-\mathrm{F}}=249\right.$ $\mathrm{Hz}), 131.2\left(\mathrm{~d}, J_{\mathrm{C}-\mathrm{F}}=8.1 \mathrm{~Hz}\right), 127.2\left(\mathrm{~d}, J_{\mathrm{C}-\mathrm{F}}=3.0 \mathrm{~Hz}\right), 116.9\left(\mathrm{~d}, J_{\mathrm{C}-\mathrm{F}}=\right.$ 22.2 Hz), 45.0, 23.3. 22.0. ${ }^{19} \mathrm{~F} \mathrm{NMR}\left(\mathrm{CDCl}_{3}, 376 \mathrm{MHz}\right):-75.8$ (s, 3 F), $-113.2(\mathrm{~s}, 1 \mathrm{~F})$.

(13) Low yields for the directing group removal procedure with $\mathrm{SmI}_{2}$ are attributed to the double extraction process carried out before the reverse-phase HPLC purification.

(14) (a) Procter, D. J.; Flowers, R. A.; Skrydstrup, F. Organic Synthesis Using Samarium Diiodide: A Practical Guide; Royal Society of Chemistry: Cambridge, 2010.

(15) (a) Kamochi, Y.; Kudo, T. Heterocycles 1993, 36, 2383. (b) Kuishima, M.; Hoiki, K.; Kono, K.; Takayuki, S.; Tani, S. Chem. Pharm. Bull. 1994, 42, 2190.

(16) Dave, P. R.; Kumar, K. A.; Duddu, R. J. Org. Chem. 2000, 65, 1207.

(17) General Procedure for Directing Group Removal with Acetyl Chloride

To a medium microwave tube (Biotage ${ }^{\circledR}, 2-5 \mathrm{~mL}$ vial) equipped with a stir bar was added the starting material $(0.217 \mathrm{mmol}, 1$ equiv) and acetyl chloride (neat, $3.0 \mathrm{~mL}$ ). The reaction was heated to $150^{\circ} \mathrm{C}$ for $3 \mathrm{~h}$. The acetyl chloride was removed under reduced pressure, and the product was redissolved in DCM (10 $\mathrm{mL})$. $\mathrm{NaOH}(1 \mathrm{M}, 10 \mathrm{~mL})$ was added. The product was extracted with $\operatorname{DCM}(2 \times 10 \mathrm{~mL})$. The volatiles were removed in vacuo, and the product was purified by reverse-phase HPLC. Isolated yield of compound 1B: $25 \%$ yield $(11 \mathrm{mg})$. LC-MS: $\mathrm{APCI}^{+}: \mathrm{m} / z[\mathrm{M}+\mathrm{H}]^{+}$ calcd for $\mathrm{C}_{13} \mathrm{H}_{16} \mathrm{NO}$ : 202.123; found: 202.153. ${ }^{1} \mathrm{H}$ NMR $\left(\mathrm{CDCl}_{3}\right.$, $400 \mathrm{MHz}$ ): $\delta=7.30$ (t, $J=7.6 \mathrm{~Hz}, 2 \mathrm{H}$ ), 7.21 (multiple peaks, $3 \mathrm{H}$ ), $4.92(\mathrm{~d}, J=12.4 \mathrm{~Hz}, 1 \mathrm{H}), 3.59$ (dd, $J=11.0,4.0 \mathrm{~Hz}, 1 \mathrm{H}), 3.32(\mathrm{~d}$, $J=11.0 \mathrm{~Hz}, 1 \mathrm{H}), 3.39(\mathrm{dd}, J=12.4,4.0 \mathrm{~Hz}, 1 \mathrm{H}), 2.23(\mathrm{t}, J=8.0 \mathrm{~Hz}$, $1 \mathrm{H}), 1.97(\mathrm{~m}, 2 \mathrm{H}), 1.47(\mathrm{~s}, 3 \mathrm{H})$. Hindered rotation of acetyl group breaks symmetry of molecule. ${ }^{13} \mathrm{C}$ NMR $\left(\mathrm{CDCl}_{3}, 101\right.$ $\mathrm{MHz}): \delta=168.9,133.8,128.8,128.5,126.9,46.8,44.6,22.5$, 21.6, 20.6, 20.1

(18) Physicochemical properties were calculated using ChemAxon (ChemAxon Component collection for Pipeline Pilot version 1.9_j55) for cLogD and BioVia's Pipeline Pilot version 9.1 calculators for NRB, NAR, HBA, HBD, MW, TPSA, N+O, Fsp3, NPR, and $\mathrm{PBF}$, with minor customization as needed. Additionally we used BioByte's cLogP calculator for calculating the octanol-water partition coefficient. Additional calculations and visualizations were conducted using PerkinElmer's Tibco Spotfire.

(19) Sauer, W. H. B.; Schwarz, M. K. J. Chem. Inf. Comput. Sci. 2003, 43, 987.

(20) Firth, N. C.; Brown, N.; Blagg, J. J. Chem. Inf. Model. 2012, 52, 2516. 